\title{
Modeling rapidly disseminating infectious disease during mass gatherings
}

\author{
Gerardo Chowell ${ }^{1,2^{*}}$, Hiroshi Nishiura ${ }^{3,4}$ and Cécile Viboud ${ }^{2}$
}

\begin{abstract}
We discuss models for rapidly disseminating infectious diseases during mass gatherings (MGs), using

influenza as a case study. Recent innovations in

modeling and forecasting influenza transmission

dynamics at local, regional, and global scales have

made influenza a particularly attractive model scenario

for MG. We discuss the behavioral, medical, and

population factors for modeling MG disease

transmission, review existing model formulations, and

highlight key data and modeling gaps related to

modeling MG disease transmission. We argue that the proposed improvements will help integrate infectiousdisease models in MG health contingency plans in the near future, echoing modeling efforts that have helped shape influenza pandemic preparedness plans in recent years.
\end{abstract}

Keywords: Model, mathematical, epidemic, outbreaks, epidemiology, mass gathering, school closure, clustering, reactive vaccination, movement, social networks/

\section{Background}

Mass gatherings (MGs) occur around the world on a relatively frequent basis, and include events as diverse as sport, religious, and educational activities [1]. MGs are typically defined as the influx of a large number of people at a specific location, for a specific purpose, and for a defined period of time; much of the available literature refers to gatherings exceeding 25,000 individuals [1]. Some MGs are spontaneous, whereas others will have been planned several years in advance, and include events as varied as royal weddings, the Olympic Games, or the Muslim Hajj pilgrimage [1].

\footnotetext{
* Correspondence: gchowell@asu.edu

'School of Human Evolution and Social Change, Arizona State University,

900 S. Cady Mall, Tempe, 85287-2402, Arizona, USA Full list of author information is available at the end of the article
}

A range of respiratory and waterborne diseases outbreaks have been reported at previous MGs, and are responsible for an estimated 14 out of 21 documented events, with occasional onward dissemination beyond the initial location of the MG [2]. A comprehensive review of infectious diseases at MGs highlights that influenza is the acute upper respiratory tract pathogen most commonly reported in these settings, partly because of its short incubation period and ubiquitous nature [2-4]. Influenza outbreaks have been reported in settings of varying scale, ranging from outbreaks in close living conditions (including troop ships [5] and airplanes [6,7]) to outbreaks in large public gatherings (such as the Winter Olympics in 2002 in Salt Lake City, USA[8] and the World Youth Day in July 2008 in Sydney [9]). Further, respiratory illness was the most common diagnosis made at a surveillance clinic during the 2008 Olympic and Paralympic Games held in Beijing and other cities of China [10]. More recently, increased 2009 pandemic influenza virus activity has been reported during several music festivals [11], and the pandemic transmission risk at the 2009 Hajj pilgrimage and the Asian South Games was deemed sufficiently important to prompt a strengthening disease surveillance systems and implementation of vaccination programs $[2,12]$. In addition, outbreaks of vaccine-preventable diseases can occur during MGs; for instance, measles outbreaks were reported during the 2008 European Football Championship in Austria and Switzerland, with onward transmission to France, Germany, and Spain [13]. Similarly, recurrent outbreaks of meningococcal meningitis have been well publicized during past Hajj pilgrimages, which attract millions of pilgrims, prompting mandatory vaccination of all participating visitors by the Government of Saudi Arabia.

Olympic events are perhaps the largest and most anticipated of all MGs, and yet, despite their scale, experience suggests that the probability of a large-scale infectious disease event is typically low. Indeed, the proportion of healthcare visits in Sydney during the 2000 Olympics for infectious diseases was less than $1 \%$. In the 2006 winter Olympics in Torino, Italy, surveillance for acute
C Biomed Central 
gastroenteritis, influenza-like illnesses, measles, and other infections found incidences similar to non-Olympics time periods [14]. Similar experiences were reported in the earlier Summer Olympics in Atlanta (1996) and Los Angeles (1984) [10]. However, epidemiological alerts can happen, as shown by an anthrax alert at the Salt Lake City airport on the first night of the 2002 Winter Olympics, which was found to be due to an environmental sample that falsely tested positive [15].

The relatively low frequency of outbreaks reported during MGs could stem from several factors. MG events are naturally ideal settings for infectious-disease transmission because of the large numbers of dense contacts. However, the probability of observing a large-scale outbreak given the introduction of a particular infectious disease introduction is relatively small, owing to the high diseaseextinction rates associated with high stochasticity in heterogeneous populations typical of MGs (for example, heterogeneity in background susceptibility, infectiousness, and vaccination rates) [16]. In addition, limited or overwhelmed disease surveillance systems can complicate early outbreak detection, reporting, and control during MGs. Moreover, for infectious diseases with long incubation periods such as tuberculosis, transmission may not be noticed during the time course of an MG event [2]. Overall, although the probability of large-scale epidemics arising from MGs seems, based on previous experience, to be low, such events do have the potential to generate unprecedented rates of morbidity and mortality at local and global levels (that is, these are low probability, high-impact events, similar to the risk of emergence of a novel pandemic virus).

A review of key data and methodological needs is useful to improve assessment of epidemic risk during MGs and to guide public-health interventions. In this article, we discuss modeling aspects and data requirements relating to modeling respiratory-disease outbreaks and responses during MG, with a specific focus on influenza and other respiratory diseases. The focus on respiratory diseases, particularly influenza, is based on the observations that respiratory infections are the most commonly reported diseases at MGs, and that influenza has been the subject of a rich modeling literature that can be used as a model for other pathogens. In particular, the $\mathrm{A} / \mathrm{H} 5 \mathrm{~N} 1$ avian influenza threat and the $2009 \mathrm{~A} / \mathrm{H} 1 \mathrm{~N} 1$ pandemic have helped improved influenza models and forecasts [17-22]. Because disease transmission during MG events is often tightly connected to the community at large via local and global transportation networks, we also considered onward transmission at broader spatial scales (city, region, world) and the relevant public-health control interventions. In the first section of this paper, we review key modeling concepts, and characterize the population and social network of MG participants. In the second section, we discuss how to incorporate these specificities into existing diseasetransmission models. In the third section, we highlight key data gaps related to models of respiratory diseases at MG, and suggest innovative approaches to fill those gaps and better inform future models.

\section{Key disease-model concepts}

The risk of infectious-disease transmission during MGs is directly related to the characteristics of the participants and their environment [2]. The effects of these factors on the risk of disease transmission can be integrated in key epidemiological quantities: the basic reproduction number, $R_{0}$, and the effective reproduction number, $R$ [23-25]. $R_{0}$ measures the average number of secondary cases generated by a primary infectious individual in a completely susceptible population. A more practical quantity is the effective reproduction number, $R$, which quantifies the potential for infectious-disease transmission in a population that may be only partially susceptible owing to prior exposure or vaccination [26]. From a probabilistic perspective, $R$ and $R_{0}$ denote the mean of the distribution of secondary cases for each single primary case in the population to account for individual-level variation in, for instance, infectiousness and contact rates [16]. $R$ can be formulated as the product of three quantities: the contact rate, the conditional probability of transmission per contact, and the duration of the infectious period [23,24], hence we can expect higher values for $R$ in crowded or confined conditions associated with MGs. Overall, $R$ of less than 1 indicates that a major epidemic is likely to occur whereas $R$ of greater than 1 indicates that transmission chains cannot be sustained. Respiratory infections cover a wide range of transmission potentials, with $R$ being estimated at 1.2 to 1.6 for seasonal influenza [27], 1.4 to 5.2 for pandemics [28-32], 15 for pertussis, 17 for measles [23], and 1.2 to 1.3 for meningococcal meningitis [33].

Another key quantity for disease control is the serial interval, which measures the time interval between successive cases and sets the time scale for epidemic growth, and hence the speed with which intervention measures need to be initiated [34]. Despite the relatively low transmission potential of influenza, outbreaks are difficult to control in real time because of its short serial interval of 2 to 3 days and the fact that a substantial fraction of transmission events occur before a case becomes symptomatic [34].

\section{Characterizing population at risk and contact networks during mass gatherings \\ Structure of disease-relevant contact network}

Perhaps the most challenging aspect of modeling infectious-disease transmission in the context of MG lies in appropriately capturing the complexity of dynamic human interactions and contact networks to provide valid and reliable predictions of transmission potential and attack 
rates. The dynamic social contact networks during MGs will depend on a number of factors, including the type (for example, confined versus open setting), size and duration of the event, the schedule of activities, the capacity of the corresponding locations in which the activities take place (for example, Olympic stadium, aquatic center), and specific crowd behavior (for example, in the case of diseases spread by aerosols, the use and sharing of plastic blowing horns by sports fans to provide audible support for their team [35]).

Most contact-network surveys have been based on cumbersome questionnaires with arbitrary physical definitions of 'social' contacts between individuals, but recent technological advances in wearable sensing devices allows unobtrusive and unsupervised quantification of contact intensity and duration. Radiofrequency identification devices were recently used to monitor in great detail the face-to-face contact patterns relevant to the spread of infectious diseases [36], particularly in primary schools $[37,38]$. Such detailed analysis of contact patterns highlighted important departures from homogeneous mixing assumptions, which should be integrated in disease models focused on outbreaks in schools or on childhood infections [38-41]. Another recent study analyzed real-time close contact interactions between conference participants, and found that the duration of contacts between the participants provided a good approximation to the epidemic dynamics compared with results obtained by modeling the full dynamic contact network [42,43]. To our knowledge, no detailed survey of contacts has been performed at MG events. A key avenue for future research would be to gain more information on contact networks in this context, perhaps by distributing sensing devices to a sample of MG participants. Although it could be challenging to enroll representative populations of MGs, recent efforts have achieved $30 \%$ participation rates for conference settings [42]. Crowd modeling is another interesting research area that offers useful tools for modeling pedestrian flow and crowd dynamics at the individual level, particularly during MGs [44]. Of note, electronic devices such as mobile phones have improved the estimation of the sizes of crowds compared with capture-recapture methods [45].

\section{Demographic characteristics}

The demographic characteristics and particularly the age distribution of the MG participants could inform the parameterization of age-specific contact rates and pre-existing immunity $[46,47]$, and thus the risk of severe disease outcomes $[48,49]$. For instance, school-age children tend to have high contact rates, are more susceptible to influenza infection, and have increased viral shedding relative to other age groups [50]. By contrast, populations of seniors experience relatively low influenza attack rates, but they are at higher risk of severe disease outcomes during seasonal influenza epidemics [51]. During pandemic seasons, however, senior populations may benefit from significant residual immunity to infection [52-54]. During the 2008 Olympic and Paralympic Games in Beijing, most (76\%) of the patients at a surveillance clinic were between the ages of 16 and 54 years [10], suggesting a relatively low susceptibility of older MG populations to influenza infection and severe outcomes, relative to other age groups. Finally, rates of hand hygiene and disease reporting are likely to be reduced during MGs, but relevant data on this behavioral aspect is lacking.

\section{Susceptibility levels and vaccination status}

Susceptibility of the MG population to the occurrence of outbreaks is a function of the collective vaccination status, previous disease exposure history, and resulting immunity. It is important to take into account the country of origin of participants, as populations from different geographical areas are exposed to different pathogens. In addition, exposure and co-infections with multiple pathogens in populations from low-income and middle-income countries could also affect immune status to common infections, such as influenza [55]. Hence, it is important to know the expected composition of participants based on country of origin and expected immunization status in order to assess susceptibility of the total MG population, which could significantly differ from that of the local population. During the 2008 Olympic and Paralympic Games in Beijing, the foreign visitors came from 46 countries, but the great majority arrived from high-income temperate regions including the USA (24\%), the Netherlands (19\%), Australia (9\%), and the UK (9\%) [10]. In addition, only $9 \%$ of foreign visitors at a surveillance clinic reported having received the influenza vaccine in their country of origin [10].

\section{Timing of MG in relation to travel patterns, climatic conditions, and school cycles}

The risk of influenza transmission at MG is connected to incoming travel patterns, local climatic conditions, and school cycles. In particular, the transmissibility of influenza has been shown to be associated with environmental conditions, as low absolute humidity has been shown to favor virus transmission and survival in the laboratory [56-58]. Influenza has marked winter seasonal patterns in temperate areas of the world, with viruses being reintroduced every winter and causing large and intense outbreaks, followed by fade-out periods in warmer months, during which little influenza activity is detected [59]. By contrast, in the Tropics, the seasonality of influenza is less defined, and the timing of virus activity varies between locales $[60,61]$. As an example, the influenza outbreaks identified during the World Youth Day occurred during the regular influenza season in Australia in winter 2008 [62]. Similarly, schools have been associated with increased rates of influenza transmission at the community level [50], and the celebration of MGs during school activity 
periods could significantly increase the risk of epidemic events.

\section{Modeling infectious-disease transmission during mass gatherings \\ Stochastic versus deterministic models}

Mathematical models of infectious-disease transmission are typically expressed as deterministic dynamical systems that capture the average epidemic behavior and are often amenable to mathematical analysis $[23,24,63,64]$. By contrast, the models most appropriate for MGs should include probabilistic components to integrate stochasticity in the risk of infection, especially in the case of smaller populations, in which demographic stochasticity will affect the risk of outbreak emergence. We produced stochastic simulations of the classic SEIR (susceptible, exposed, infectious, recovered) transmission model tailored to the epidemiology of influenza [65] (Figure 1). It is also important to use probabilistic models to consider shorter temporal scales during MGs and compare these with communitylevel transmission. Moreover, stochastic models allow the estimation of the probability that introduction of initial case(s) will trigger a major epidemic, which is also significantly affected by host heterogeneity (for example, age,

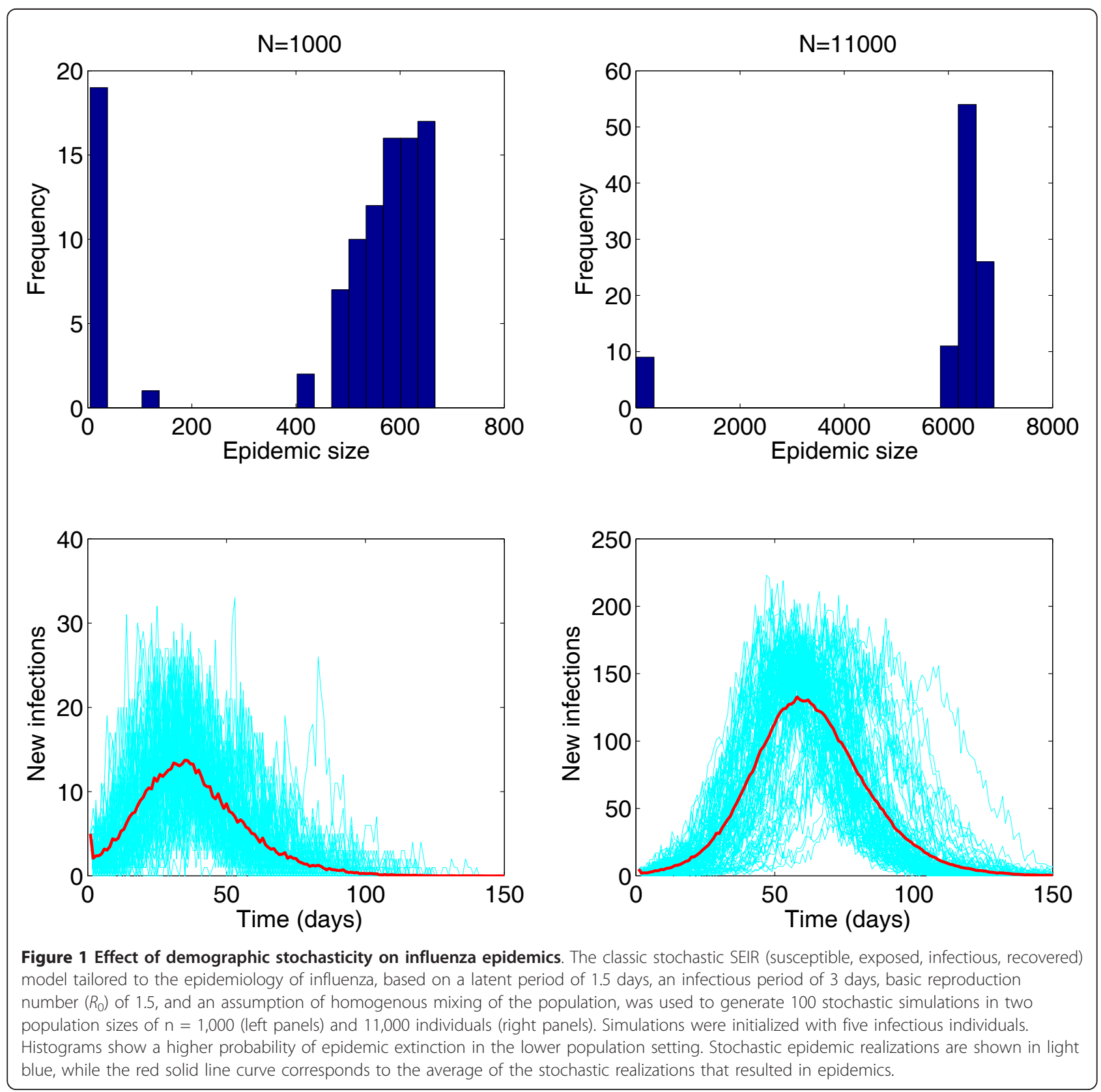


vaccination status) and mixing patterns (for example, confined space in airplane, large conference hall).

\section{Mass gathering contact structure}

In general, infectious-disease models using explicit contact-network approaches can be classified as agent-based, individual-based, and spatially structured models, according to the level of detail used to model disease transmission. Agent-based models are very flexible, and can incorporate heterogeneities in the interactions, behaviors, and susceptibility of individuals, which make them particularly suitable for the analysis of collective dynamics of complex systems [66]. Models relying on detailed information on individual-level activities have been used to model the spread of rapidly disseminating infectious diseases, including influenza, and to help assess intervention strategies [19,20,67-73]. A slightly cruder approach is provided by individual-based models, which are often based on static networks of individual interactions [74,75]. Spatially structured epidemic models consider subsets of the population categorized by geographic location, with interactions between these subpopulations based on human mobility patterns [76-78] (for example, governed by gravity laws, whereby larger population centers tend to interact with higher probability) and age-specific contact rates based on contact survey data [46].

The choice of the underlying assumptions about the contact-structure profile will depend on the MG population. For instance, in the case of infectious-disease transmission in small populations within confined settings, such as disease transmission in Navy ships [79] and correctional facilities [64], assuming a well-mixed population could be reasonable. However, recent work has identified significant departures from homogenous mixing assumptions during specific MGs, including conference settings [42]. The role of the contact-network structure on transmission dynamics is illustrated in Figure 2; faster diseasetransmission rates are seen in random-mixing structures than in small-world network structures [74].

\section{Airborne transmission in confined spaces}

Quantitative microbial risk-assessment models have been successful in modeling airborne transmission of respiratory pathogens in confined spaces, such as influenza and tuberculosis on airplanes [6,80-82], and quantifying infection risk as a function of host, pathogen, and environmental factors [83-86]. In particular, the Wells-Riley model [87-90] has been shown to be useful for well-mixed confined spaces, which can readily incorporate environmental and pathogen-specific variables such as room ventilation rates, pulmonary respiratory rates, number of infectious individuals, and infectivity, as a function of virus concentration exhaled by infectious individuals [91]. This model has been widely used in the microbial dose-response modeling literature [92], and was successful in assessing the risk of transmission in different areas of a closed-space environment and calculating the potential number of new infections generated over a specific time period.

Table 1 summarizes the differences between the quantitative risk-assessment and the dynamic transmission models. Dose-response models are traditionally used to understand dose-response mechanisms and allowable microbial concentration in foods and water, but they can also be combined with other epidemiological models. A typical example is a model for point source outbreaks caused by certain exposure doses (for example, the Sverdlovsk anthrax leak), which can provide estimates for the total number of cases, the time of exposure, and the dose $[92,93]$. Another useful approach is to account for the dose-response nature of the risk of infection in traditional disease-transmission models, allowing adjustment for different transmission probabilities by route of transmission (aerosols, droplets) [94].

\section{The role of multiple initial infectious sources}

An important modeling consideration is the initial number of infectious individuals, and their geographical location and contact networks, particularly in the context of highly heterogeneous MG populations. Indeed, the probability of an epidemic unfolding and the rate of growth rate in the number of infections will depend upon the number of initial infectious individuals and their spatial location within the MG contact network [65]. This also has relevance to the potential deliberate release of infectious diseases during MGs. To illustrate this point, we show how outbreak size increases with the initial number of infectious individuals, using a small-world contact-network structure of 1,000 individuals (Figure 3).

\section{Spatial scale considerations and global transmission models}

Disease transmission during MG events cannot be disconnected from the rest of the population, because of the tight connections to the community at large via local, regional, and global transportation networks. For instance, in the context of large MGs such as the Olympics Games or the Soccer World Cups, given the scale of the event and the many neighborhoods and sometimes cities involved, models appropriate for a large city or a network of cities may be more appropriate than models limited to a confined space. Hence, large-scale transmission models and population-wide public-health control interventions are also useful to discuss in the context of MG events.

In the event of an infectious-disease outbreak during a MG, worldwide travel patterns originating from the MG population could disseminate the outbreak on a global scale within a matter of weeks [95]. For instance, following the identification of the $2009 \mathrm{~A} / \mathrm{H} 1 \mathrm{~N} 1$ influenza pandemic in Mexico and California in late March 2009, the novel pandemic virus was detected within a few weeks in the 20 countries with highest volume of passengers arriving from Mexico [96]. 

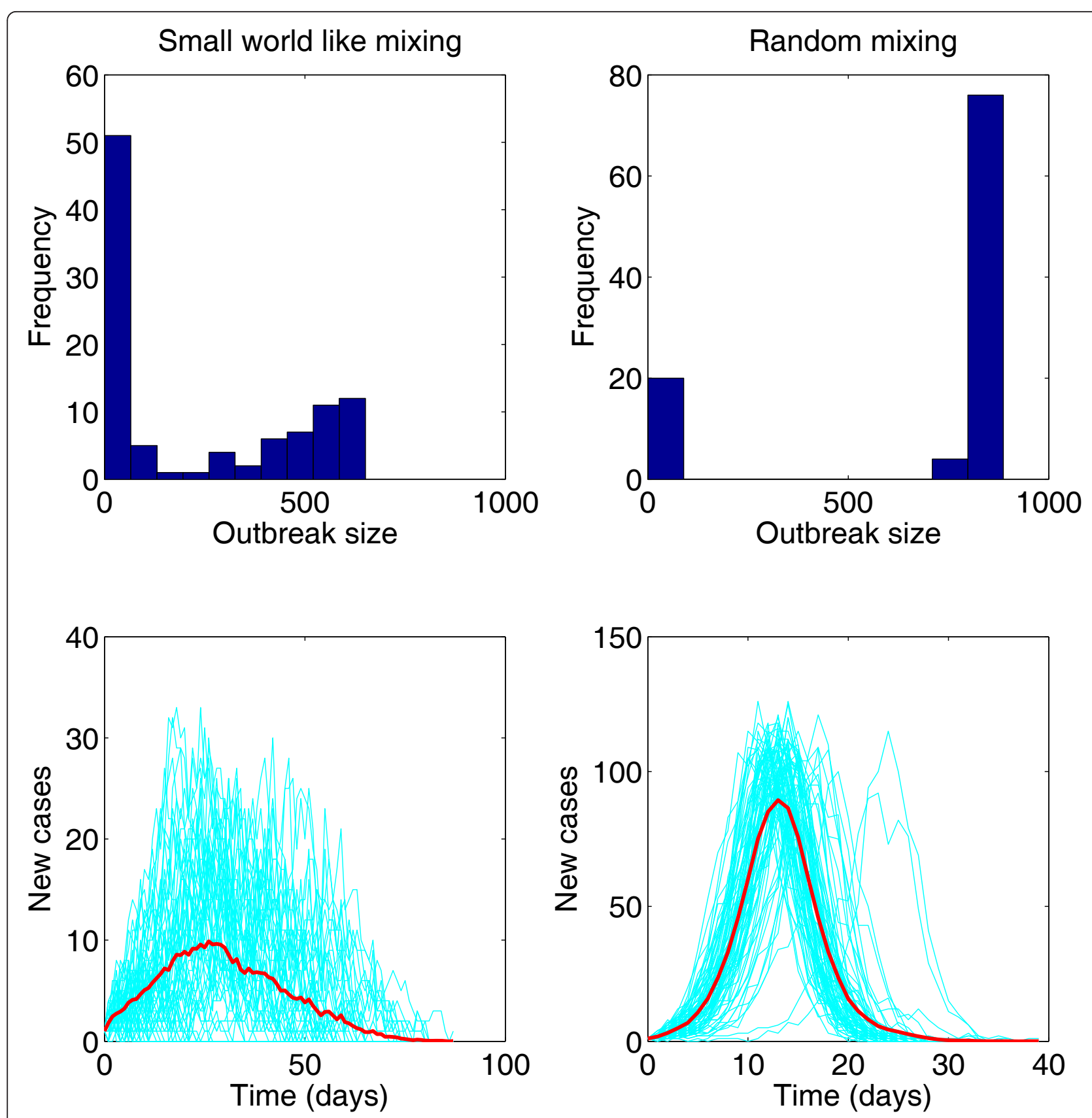

Figure 2 Effect of contact-network structure on influenza epidemics. The classic stochastic SEIR (susceptible, exposed, infectious, recovered) model was tailored to the epidemiology of influenza, based on a latent period of 1.5 days, an infectious period of 3 days, and fixed transmission probability per contact, simulated using two different contact networks: 1) a small-world contact network based on the model of Watts and Strogatz [74], with an average degree of 4 and disorder parameter (p) of 0.1 in a population of 1,000 individuals (left panels) and 2) in a random network model with an average degree of 4 (right panels) with the same population size. Histograms show the distribution of outbreak sizes for both network topologies when everything else is kept fixed. Epidemic realizations are shown in blue, while the red solid line curve corresponds to the average of the stochastic realizations that resulted in epidemics.

Large-scale computational transmission models parameterized with high-volume air-traffic data and countrylevel seasonality factors are being increasingly used to assess the global transmission patterns of emerging infectious diseases and the effectiveness of control measures
$[18,77,97,98]$. Such large-scale modeling efforts predicted that an early peak of pandemic influenza A/H1N1 virus activity would occur in October/November 2009 in the Northern hemisphere, several weeks before vaccination campaigns could be carried out, and that antiviral use 
Table 1 Contrasting quantitative microbial risk-assessment models and infectious disease-transmission models.

\begin{tabular}{lll}
\hline Modeling aspects & $\begin{array}{l}\text { Quantitative microbial risk-assessment } \\
\text { model }\end{array}$ & Dynamic transmission model \\
\hline Non-linear dynamics & Usually no & Usually yes \\
\hline Environmental sources & Yes & Usually no \\
\hline $\begin{array}{l}\text { Inclusion of uncertainty/ } \\
\text { stochasticity }\end{array}$ & Yes & $\begin{array}{l}\text { Case-by-case basis (deterministic dynamical systems, stochastic, hybrid } \\
\text { models) }\end{array}$ \\
\hline Time scale & Days & Weeks to months \\
\hline Population size & $\begin{array}{l}\text { Thousands (music festival) to millions (Hajj } \\
\text { pilgrimage) }\end{array}$ & Hundred thousands to millions \\
\hline Population density & High & Low to high \\
\hline Model structure & Spatial-temporal network (Summer Olympics); & $\begin{array}{l}\text { Age-structured, random-mixing populations; patch models; household- } \\
\text { level models; large-scale individual-level models }\end{array}$ \\
\hline $\begin{array}{l}\text { Stochastic disease } \\
\text { extinction }\end{array}$ & Yes & Unlikely \\
\hline Endemicity & No & Yes \\
\hline $\begin{array}{l}\text { Contribution of super- } \\
\text { spreading events }\end{array}$ & High & Low to moderate \\
\hline
\end{tabular}

could delay peak pandemic timing. In regards to the effects of interventions on global transmission patterns, multiple studies have concluded that substantial reductions in air travel could only provide a short delay in pandemic progression [99-102].

Overall, network-based approaches have become useful tools to model the transmission dynamics of infectious diseases and control interventions on city, regional, and global scales $[19,20,67-69,74,103,104]$. These simulation models are currently underused in the context of MGs. To our knowledge, only a single network-based modeling study has examined how outbreak size may depend on the timing of an MG event, relative to the temporal course of an influenza pandemic [105]. The MG event was modeled as a change in population mixing.

\section{Key data needs for large-scale simulation models}

Global transmission models rely on large amounts of data on demographics, population movements, and age-specific contact rates. High-resolution demographic and age-specific contact data has become available for a number of areas, including the USA $[19,106]$, and southeast Asia [20,107], while age-specific contact rates have been derived from population surveys for a number of European countries [46]. However, travel patterns before and after the MG event are naturally difficult to ascertain well in advance of the event, but are essential data for anticipating the expected composition of the MG and the potential global infectious disease-transmission patterns. Analysis of international travel data from previous Summer Olympics suggests that changes in travel patterns to the host city are difficult to predict months in advance [12]. Moreover, highresolution contact rate data and within-country connectivity data are not available for most countries. Equally important is the need for country-specific historical immunization coverage data to assess the risk of importation to and from different locations. Finally, additional information on the temperature, humidity, ventilation settings, and capacity of confined environments specific to MGs, such as indoor stadiums (Olympics) and mosques (the Hajj), would be useful to tailor environmental risk models to MGs.

\section{Public-health interventions during mass gatherings}

The decision-making process on the type and intensity of interventions to put in place to control a MG outbreak will depend on our ability to detect early cases, characterize the transmission potential and severity of the associated pathogen, and implement interventions rapidly [108]. Overall, the timing of start of interventions will depend on the epidemiology of the infectious disease and the availability of surveillance data that is representative of the general population. Cancellation of large public gatherings has been successfully implemented during past influenza pandemics $[4,9,25,109]$; however, cancellation of a major MG event such as the Summer Olympics as a result of perceived infectious-disease transmission risk could be counterproductive, because of potential for rapid global spread. Instead, recommendations to use face-masks and increase hygiene measures could prove to be effective mitigation strategies, together with preventive or reactive vaccination in the early stages of the outbreak, as shown in past epidemics of influenza, meningococcal meningitis, and measles [69,110-114]. This is particularly important in light of outbreaks of measles and mumps reported at past MGs [2], and the difficulty in reaching the critical vaccination coverage rate against childhood infectious diseases in many European countries [115]. The importance of putting in place targeted vaccination strategies against influenza and other respiratory pathogens prior to any MG event cannot be overemphasized. 


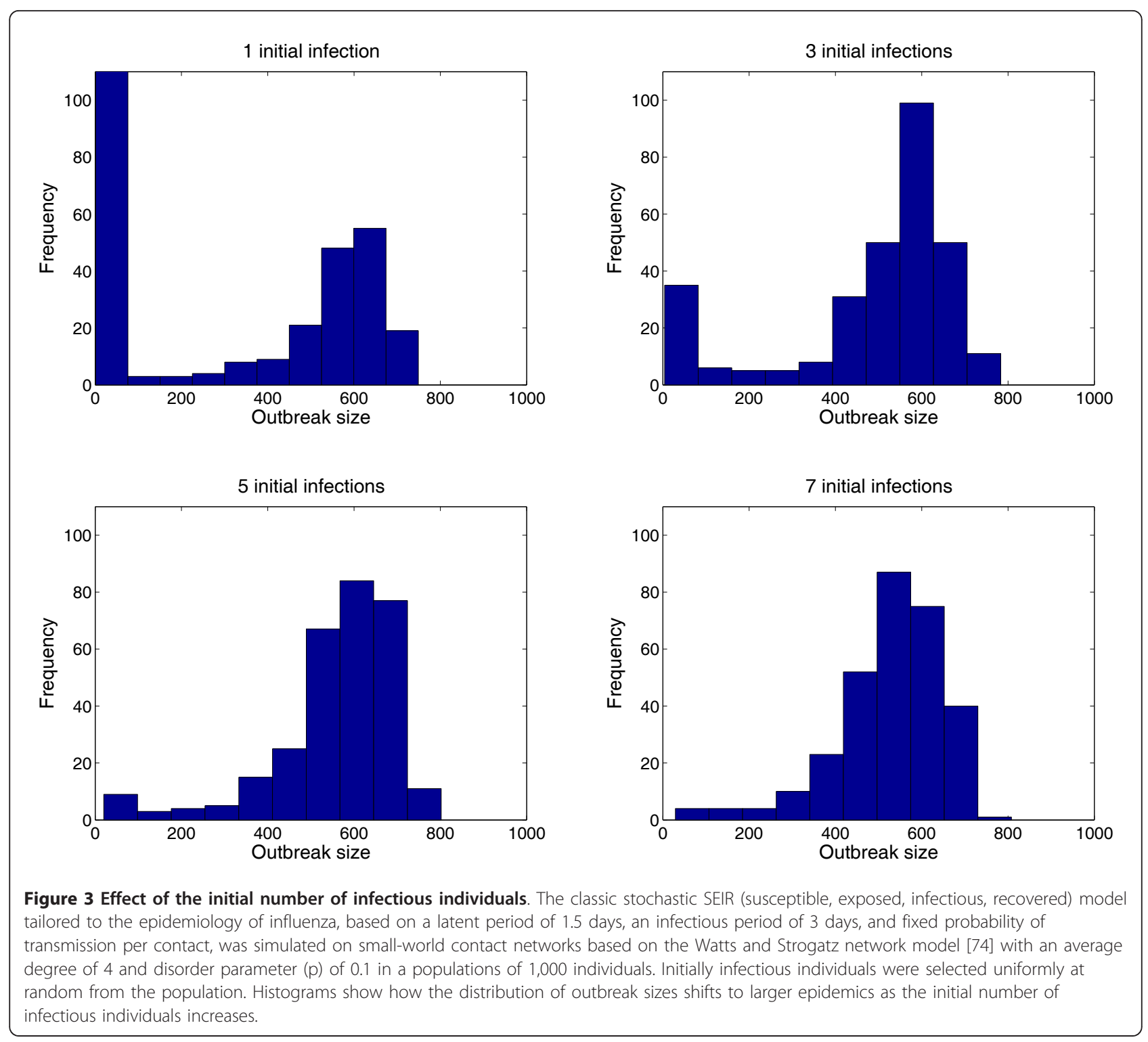

In the extreme situation in which evidence suggests the potential for increased rates of hospitalization and mortality, stringent interventions could be justifiable, including imposing movement restrictions on MG participants to avoid or slow the importation of cases [86] to high-risk countries, concurrent with a reactive vaccination strategy [116].

The composition and dynamics of MG events as large as the Olympics are complex. Recent data indicate that influxes of several million visitors are typically expected, including tens of thousands of journalists and athletes from a couple of hundred nationalities. Moreover, competitions take place in a number of open and confined settings, with capacities ranging from a few thousand to tens of thousands. The expected age distribution of participants is relatively young, with the majority being young and middle-aged adults [10], which is the age group that experienced the highest death rates during the most recent influenza pandemic [117]. Moreover, recent data indicate that only a small fraction of the participant population is expected to have received the seasonal influenza vaccine in their country of origin before the start of the competitions $[10,118]$. Public-health preparedness planning is very intense during Olympic Games. This was illustrated by the 2012 London Summer Olympics, for which the UK Health Protection Agency set up an enhanced disease-monitoring system including laboratory surveillance, clinical case reporting, and syndromic surveillance based on patient symptoms [119-121], and surveillance was conducted using a lower than usual detection threshold. However, to our knowledge, infectious disease-transmission models were not integrated in any of these preparedness efforts. 


\section{Future directions}

Below we summarize the data and modeling gaps that we have identified throughout this review, which must be filled to improve infectious-disease models for MGs. Because no detailed survey of MG contact networks has been carried out, a key avenue for future research would be to gain more information on the patterns and duration of human interactions during MG events, perhaps by distributing innovative contact-sensing devices to a sample of MG participants [36]. The Olympic Games, Soccer World Cups, and annual Hajj pilgrimages offer an interesting opportunity to study large crowds in the context of infectious-disease transmission. Although it is not feasible to monitor contact patterns in the entire MG population, information from a representative sample would be useful, and participation in previous contact-sensing device studies has been high. Ideally, such studies should be combined with enhanced monitoring of disease activity, including simultaneously testing for several pathogens (for example, using multiplex PCR) and incorporating innovative approaches for disease surveillance (for example, exploiting web-based technologies, and datagathering and dissemination methods via smart phones) [122].

Comprehensive modeling studies are lacking to assess the cost-effectiveness of intervention strategies such as movement restrictions and reactive vaccination in the context of infectious-disease transmission during MGs. This is partly because of our limited knowledge of crucial demographic and susceptibility characteristics of the population and the relevant contact structure for disease transmission. In parallel, the higher levels of computational power now available is facilitating the development of extremely detailed transmission models at multiple spatial scales $([18,19,22,107,123]$. Another key data gap is the difficulty in ascertaining up-to-date air-travel patterns relating to MG events as well as country-specific repositories of demographic, contact rates, and immunization data for childhood and other infectious diseases, which would be needed for appropriate calibration of large-scale transmission models involving large numbers of international visitors. Finally, it would be useful to validate infectiousdisease models for MGs against historical outbreaks that have been well documented in the literature, especially given the stochastic nature of these outbreaks in heterogeneous populations [2].

We note that the number of efforts to integrate microbial risk-assessment modeling and dynamic populationlevel transmission modeling approaches remains limited [92-94]. Hence, the integration of quantitative risk models into large-scale dynamic transmission models has the potential to improve predictive capabilities in relation to epidemic transmission patterns and prospects for outbreak control, particularly in the context of disease transmission at MGs. Such modeling approaches could follow a hierarchical structure by connecting disease-transmission processes on different spatial scales [86].

\section{Conclusions}

Comprehensive modeling studies are needed to assess the cost-effectiveness of intervention strategies against infectious disease arising during large MGs such as the Summer Olympics and the annual Hajj events. These studies will heavily rely on our ability to quantify population mixing characteristics during MG events; anticipate air-travel patterns before and after the MG event; gather country-specific repositories of demographic factors, contact rates, and immunization rates for childhood and other infectious diseases; and estimate the potential effect of collective behavioral changes during MG events. Further, development of novel mathematical and statistical approaches specific to MGs, and integration of existing approaches, would be useful to provide more appropriate models, which could be tested against historical events [124]. Finally, MG preparedness and contingency intervention plans to mitigate infectiousdisease transmission could incorporate some of these modeling research, inspired by influenza modeling efforts that have helped shape pandemic preparedness plans in recent years $[18,19,22,99-102,107,123]$.

\section{Author details \\ 'School of Human Evolution and Social Change, Arizona State University, 900 S. Cady Mall, Tempe, 85287-2402, Arizona, USA. ²Division of Epidemiology and Population Studies, Fogarty International Center, National Institutes of Health, 31 Center Dr, MSC 2220, Bethesda, 20892-2220, Maryland, USA. ${ }^{3}$ School of Public Health, The University of Hong Kong, Cyberport Road 100, Pokfulam, Hong Kong Special Administrative Region, China. ${ }^{4}$ PRESTO (Precursory Research for Embryonic Science and Technology), Japan Science and Technology Agency, Honcho Kawaguchi 4-1-8, Saitama 332-0012, Japan.}

\section{Authors' contributions}

All the authors contributed to the writing and editing of the manuscript. All the authors have read and approved the manuscript for publication.

\section{Competing interests}

The authors declare that they have no competing interests.

Received: 4 May 2012 Accepted: 7 December 2012

Published: 7 December 2012

\section{References}

1. World Health Organization (WHO): Key considerations. Communicable disease alert and response for mass gatherings. Geneva, Switzerland: WHO; 2008.

2. Abubakar I, Gautret P, Brunette GW, Blumberg L, Johnson D, Poumerol G, Memish ZA, Barbeschi M, Khan AS: Global perspectives for prevention of infectious diseases associated with mass gatherings. Lancet Infect Dis 12:66-74.

3. Hatchett RJ, Mecher CE, Lipsitch M: Public health interventions and epidemic intensity during the 1918 influenza pandemic. Proc Natl Acad Sci USA 2007, 104:7582-7587.

4. Bootsma MC, Ferguson NM: The effect of public health measures on the 1918 influenza pandemic in U.S. cities. Proc Natl Acad Sci USA 2007, 104:7588-7593. 
5. White LF, Pagano M: Transmissibility of the influenza virus in the 1918 pandemic. PLoS ONE 2008, 3:e1498.

6. Mangili A, Gendreau MA: Transmission of infectious diseases during commercial air travel. Lancet 2005, 365:989-996.

7. Baker MG, Thornley CN, Mills C, Roberts S, Perera S, Peters J, Kelso A, Barr I, Wilson N: Transmission of pandemic A/H1N1 2009 influenza on passenger aircraft: retrospective cohort study. BMJ 2010, 340:c2424.

8. Gundlapalli AV, Rubin MA, Samore MH, Lopansri B, Lahey T, McGuire HL, Winthrop KL, Dunn JJ, Willick SE, Vosters RL, Waeckerle JE, Carroll KC, Gwaltney JM Jr, Hayden FG, Elstad MR, Sande MA: Influenza, Winter Olympiad, 2002. Emerg Infect Dis 2006, 12:144-146.

9. Chowell G, Echevarría-Zuno S, Viboud C, Simonsen L, Tamerius J, Miller MA, Borja-Aburto VH: Characterizing the epidemiology of the 2009 influenza A/H1N1 pandemic in Mexico. PloS Medicine 2011, 8:e1000436.

10. Jentes ES, Davis XM, Macdonald S, Snyman PJ, Nelson H, Quarry D, Lai I, van Vliet EW, Balaban V, Marano C, Mues K, Kozarsky P, Marano N: Health risks and travel preparation among foreign visitors and expatriates during the 2008 Beijing Olympic and Paralympic Games. Am J Trop Med Hyg 2010, 82:466-472.

11. Gutierrez I, Litzroth A, Hammadi S, Van Oyen H, Gerard C, Robesyn E, Bots J, Faidherbe MT, Wuillaume F: Community transmission of influenza A (H1N1)v virus at a rock festival in Belgium, 2-5 July 2009. Euro Surveill 2009, 14.

12. Khan K, McNabb SJ, Memish ZA, Eckhardt R, Hu W, Kossowsky D, Sears J, Arino J, Johansson A, Barbeschi M, McCloskey B, Henry B, Cetron M, Brownstein JS: Infectious disease surveillance and modelling across geographic frontiers and scientific specialties. Lancet Infect Dis 2012, 12:222-230.

13. Steffens I, Martin R, Lopalco P: Spotlight on measles 2010: measles elimination in Europe - a new commitment to meet the goal by 2015 . Euro Surveill 15.

14. Franke $F$, Coulon $L$, Renaudat $C$, Euillot $B$, Kessalis $N$, Malfait $P$ : Epidemiological surveillance implemented in southeast France during the 2006 Olympic Winter Games. Euro Surveill 2006, 11:E060907-060906.

15. BBC News. Anthrax scare at Salt Lake City. [http://news.bbc.co.uk/2/hi/ americas/1817831.stm].

16. Lloyd-Smith JO, Schreiber SJ, Kopp PE, Getz WM: Superspreading and the effect of individual variation on disease emergence. Nature 2005, 438:355-359.

17. Glasser J, Feng Z, Moylan A, Del Valle S, Castillo-Chavez C: Mixing in agestructured population models of infectious diseases. Math Biosci 2012, 235:1-7.

18. Balcan D, Hu H, Goncalves B, Bajardi P, Poletto C, Ramasco JJ, Paolotti D, Perra N, Tizzoni M, Van den Broeck W, Colizza V, Vespignani A: Seasonal transmission potential and activity peaks of the new influenza $A(H 1 N 1)$ : a Monte Carlo likelihood analysis based on human mobility. BMC Med 2009, 7:45.

19. Ferguson NM, Cummings DA, Fraser C, Cajka JC, Cooley PC, Burke DS: Strategies for mitigating an influenza pandemic. Nature 2006, 442:448-452.

20. Ferguson NM, Cummings DA, Cauchemez S, Fraser C, Riley S, Meeyai A, lamsirithaworn S, Burke DS: Strategies for containing an emerging influenza pandemic in Southeast Asia. Nature 2005, 437:209-214.

21. Longini IM Jr, Halloran ME, Nizam A, Yang Y: Containing pandemic influenza with antiviral agents. Am J Epidemiol 2004, 159:623-633.

22. Chao DL, Halloran ME, Obenchain VJ, Longini IM Jr: FluTE, a publicly available stochastic influenza epidemic simulation model. PLoS Comput Biol 6:1000656.

23. Anderson RM, May RM: Infectious diseases of humans. Oxford: Oxford University Press; 1991.

24. Diekmann O, Heesterbeek J: Mathematical epidemiology of infectious diseases: model building, analysis and interpretation. Wiley; 2000.

25. Nishiura H, Castillo-Chavez C, Safan M, Chowell G: Transmission potential of the new influenza $A(\mathrm{H} 1 \mathrm{~N} 1)$ virus and its age-specificity in Japan. Euro Surveill 2009, 14.

26. Chowell G, Miller MA, Viboud C: Seasonal influenza in the United States, France, and Australia: transmission and prospects for control. Epidemiol Infect 2007, 1-13.

27. Chowell G, Miller MA, Viboud C: Seasonal influenza in the United States, France, and Australia: transmission and prospects for control. Epidemiol Infect 2008, 136:852-864.

28. Mills CE, Robins JM, Lipsitch M: Transmissibility of 1918 pandemic influenza. Nature 2004, 432:904-906.
29. Andreasen V, Viboud C, Simonsen L: Epidemiologic characterization of the 1918 influenza pandemic summer wave in Copenhagen: implications for pandemic control strategies. J Infect Dis 2008, 197:270-278.

30. Chowell G, Ammon CE, Hengartner NW, Hyman JM: Transmission dynamics of the great influenza pandemic of 1918 in Geneva, Switzerland: assessing the effects of hypothetical interventions. J Theor Biol 2006, 241:193-204.

31. Nishiura $\mathrm{H}$ : Time variations in the transmissibility of pandemic influenza in Prussia, Germany, from 1918-19. Theor Biol Med Model 2007, 4:20.

32. Chowell G, Viboud C, Simonsen L, Miller MA, Acuna-Soto R: Mortality patterns associated with the 1918 influenza pandemic in Mexico: evidence for a spring herald wave and lack of preexisting immunity in older populations. J Infect Dis 2010, 202:567-575.

33. Trotter CL, Gay NJ, Edmunds WJ: Dynamic models of meningococcal carriage, disease, and the impact of serogroup $C$ conjugate vaccination. Am J Epidemiol 2005, 162:89-100.

34. Fraser C, Riley S, Anderson RM, Ferguson NM: Factors that make an infectious disease outbreak controllable. Proc Natl Acad Sci USA 2004, 101:6146-6151.

35. Lai KM, Bottomley C, McNerney R: Propagation of respiratory aerosols by the vuvuzela. PLoS One 2011, 6:e20086.

36. Cattuto C, Van den Broeck W, Barrat A, Colizza V, Pinton JF, Vespignani A: Dynamics of person-to-person interactions from distributed RFID sensor networks. PLoS One 2010, 5:e11596.

37. Stehlé J, Voirin N, Barrat A, Cattuto C, Isella L, Pinton JF, Quaggiotto M, Van den Broeck W, Régis C, Lina B, Vanhems P: High-resolution measurements of face-to-face contact patterns in a primary school. PLoS One 2011, 6 e23176.

38. Cauchemez S, Bhattarai A, Marchbanks TL, Fagan RP, Ostroff S, Ferguson NM, Swerdlow D: Role of social networks in shaping disease transmission during a community outbreak of 2009 H1N1 pandemic influenza. Proc Natl Acad Sci USA 2011, 108:2825-2830.

39. Pitzer VE, Burgner D, Viboud C, Simonsen L, Andreasen V, Steiner CA, Lipsitch M: Modelling seasonal variations in the age and incidence of Kawasaki disease to explore possible infectious aetiologies. Proc Biol Sci 2012, 279:2736-43.

40. Pitzer VE, Lipsitch M: Exploring the relationship between incidence and the average age of infection during seasonal epidemics. J Theor Biol 2009, 260:175-185

41. Babad HR, Nokes DJ, Gay NJ, Miller E, Morgan-Capner P, Anderson RM: Predicting the impact of measles vaccination in England and Wales: model validation and analysis of policy options. Epidemiol Infect 1995, 114:319-344.

42. Stehlé J, Voirin N, Barrat A, Cattuto C, Colizza V, Isella L, Régis C, Pinton JF, Khanafer N, Van den Broeck W, Vanhems P: Simulation of an SEIR infectious disease model on the dynamic contact network of conference attendees. BMC Med 2011, 9:87.

43. Blower S, Go MH: The importance of including dynamic social networks when modeling epidemics of airborne infections: does increasing complexity increase accuracy? BMC Med 2011, 9:88.

44. Johansson A, Batty M, Hayashi K, Al Bar O, Marcozzi D, Memish ZA: Crowd and environmental management during mass gatherings. Lancet Infect Dis 12:150-156.

45. Watson $R$, Yip P: How many were there when it mattered? Significance 2011, 8:104-107.

46. Mossong J, Hens N, Jit M, Beutels P, Auranen K, Mikolajczyk R, Massari M, Salmaso S, Tomba GS, Wallinga J, Heijne J, Sadkowska-Todys M, Rosinska M, Edmunds WJ: Social contacts and mixing patterns relevant to the spread of infectious diseases. PLoS Med 2008, 5:e74.

47. Del Valle SY, Hyman JM, Hethcote HW, Eubank SG: Mixing patterns between age groups in social networks. Social Networks 2007, 29:539-554.

48. Presanis AM, De Angelis D, Hagy A, Reed C, Riley S, Cooper BS, Finelli L, Biedrzycki P, Lipsitch M: The severity of pandemic H1N1 influenza in the United States, from April to July 2009: a bayesian analysis. PLoS Med 2009, 6:e1000207.

49. Nishiura $\mathrm{H}$ : Case fatality ratio of pandemic influenza. Lancet Infect Dis 2010, 10:443-444.

50. Cauchemez S, Ferguson NM, Wachtel C, Tegnell A, Saour G, Duncan B, Nicoll A: Closure of schools during an influenza pandemic. Lancet Infect Dis 2009, 9:473-481. 
51. Charu V, Chowell G, Palacio Mejia LS, Echevarría-Zuno S, Borja-Aburto VH, Simonsen L, Miller MA, Viboud C: Mortality burden of the A/H1N1 pandemic in Mexico: a comparison of deaths and years of life lost to seasonal influenza. Clin Infect Dis 2011, 53:985-93.

52. Hancock K, Veguilla V, Lu X, Zhong W, Butler EN, Sun H, Liu F, Dong L, DeVos JR, Gargiullo PM: Cross-reactive antibody responses to the 2009 pandemic H1N1 influenza virus. N Engl J Med 2009, 361:1945-1952.

53. Chowell G, Bertozzi SM, Colchero MA, Lopez-Gatell H, Alpuche-Aranda C, Hernandez M, Miller MA: Severe respiratory disease concurrent with the circulation of H1N1 influenza. N Engl J Med 2009, 361:674-679.

54. Fisman DN, Savage R, Gubbay J, Achonu C, Akwar H, Farrell DJ, Crowcroft NS, Jackson P: Older age and a reduced likelihood of 2009 H1N1 virus infection. N Engl J Med 2009, 361:2000-2001.

55. Cohen C, Simonsen L, Kang JW, Miller M, McAnerney J, Blumberg L, Schoub B, Madhi SA, Viboud C: Elevated influenza-related excess mortality in South African elderly individuals, 1998-2005. Clin Infect Dis 2010, 51:1362-1369.

56. Steel J, Staeheli P, Mubareka S, Garcia-Sastre A, Palese P, Lowen AC Transmission of pandemic H1N1 influenza virus and impact of prior exposure to seasonal strains or interferon treatment. J Virol 2011, 84:21-26.

57. Lowen AC, Mubareka S, Steel J, Palese P: Influenza virus transmission is dependent on relative humidity and temperature. PLoS Pathog 2007, 3:1470-1476.

58. Mubareka S, Lowen AC, Steel J, Coates AL, Garcia-Sastre A, Palese P: Transmission of influenza virus via aerosols and fomites in the guinea pig model. J Infect Dis 2009, 199:858-865.

59. Viboud C, Alonso WJ, Simonsen L: Influenza in tropical regions. PLoS Med 2006, 3:e89

60. Alonso WJ, Viboud C, Simonsen L, Hirano EW, Daufenbach LZ, Miller MA: Seasonality of influenza in Brazil: a traveling wave from the Amazon to the subtropics. Am J Epidemiol 2007, 165:1434-1442.

61. Russell CA, Jones TC, Barr IG, Cox NJ, Garten RJ, Gregory V, Gust ID, Hampson AW, Hay AJ, Hurt AC, de Jong JC, Kelso A, Klimov Al, Kageyama T, Komadina N, Lapedes AS, Lin YP, Mosterin A, Obuchi M, Odagiri T, Osterhaus AD, Rimmelzwaan GF, Shaw MW, Skepner E, Stohr K, Tashiro M, Fouchier RA, Smith DJ: The global circulation of seasonal influenza A (H3N2) viruses. Science 2008, 320:340-346.

62. Blyth CC, Foo H, van Hal SJ, Hurt AC, Barr IG, MCPhie K, Armstrong PK Rawlinson WD, Sheppeard V, Conaty S, Staff M, Dwyer DE: Influenza outbreaks during World Youth Day 2008 mass gathering. Emerg Infect Dis 2010, 16:809-815.

63. Castillo-Chavez C, Castillo-Garsow CW, Yakubu AA: MSJAMA. Mathematical models of isolation and quarantine. JAMA 2003, 290:2876-2877.

64. Kajita E, Okano JT, Bodine EN, Layne SP, Blower S: Modelling an outbreak of an emerging pathogen. Nat Rev Microbiol 2007, 5:700-709.

65. Chowell G, Castillo-Chavez C: Worst-case scenarios and epidemics. In Bioterrorism: Mathematical and Modeling Approaches in Homeland Security. Edited by: C.Castillo-Chavez HTBa. SIAM's series Frontiers in Applied Mathematics; 2003

66. Macal CM, North MJ: Tutorial on agent-based modelling and simulation. Journal of Simulation 2010, 4:151-162.

67. Eubank S, Guclu H, Kumar VS, Marathe MV, Srinivasan A, Toroczkai Z, Wang N: Modelling disease outbreaks in realistic urban social networks. Nature 2004, 429:180-184.

68. Longini IM Jr, Halloran ME, Nizam A, Yang Y, Xu S, Burke DS, Cummings DA, Epstein JM: Containing a large bioterrorist smallpox attack: a computer simulation approach. Int J Infect Dis 2007, 11:98-108.

69. Halloran ME, Longini IM Jr, Nizam A, Yang Y: Containing bioterrorist smallpox. Science 2002, 298:1428-1432.

70. Ciofi degli Atti ML, Merler S, Rizzo C, Ajelli M, Massari M, Manfredi P, Furlanello C, Scalia Tomba G, lannelli M: Mitigation measures for pandemic influenza in Italy: an individual based model considering different scenarios. PLoS One 2008, 3(3):e1790.

71. Carrat F, Pelat C, Levy-Bruhl D, Bonmarin I, Lapidus N: Planning for the next influenza H1N1 season: a modelling study. Bmc Infectious Diseases 2010, 10.

72. Merler S, Ajelli M, Rizzo C: Age-prioritized use of antivirals during an influenza pandemic. BMC Infect Dis 2009, 9:117.

73. Chowell G, Hyman JM, Eubank S, Castillo-Chavez C: Scaling laws for the movement of people between locations in a large city. Phys Rev E Stat Nonlin Soft Matter Phys 2003, 68:066102.
74. Watts DJ, Strogatz SH: Collective dynamics of 'small-world' networks. Nature 1998, 393:440-442.

75. Pastor-Satorras R, Vespignani A: Epidemic spreading in scale-free networks. Phys Rev Lett 2001, 86:3200-3203.

76. Viboud C, Bjornstad ON, Smith DL, Simonsen L, Miller MA, Grenfell BT: Synchrony, waves, and spatial hierarchies in the spread of influenza. Science 2006, 312:447-451.

77. Merler S, Ajelli M: The role of population heterogeneity and human mobility in the spread of pandemic influenza. Proc Biol Sci 277:557-565.

78. Eggo RM, Cauchemez S, Ferguson NM: Spatial dynamics of the 1918 influenza pandemic in England, Wales and the United States. J R Soc Interface 8:233-243.

79. Outbreak of 2009 pandemic influenza A (H1N1) on a Peruvian Navy ship June-July 2009. MMWR Morb Mortal Wkly Rep 2010, 59:162-165.

80. Moser MR, Bender TR, Margolis HS, Noble GR, Kendal AP, Ritter DG: An outbreak of influenza aboard a commercial airliner. Am J Epidemiol 1979, 110:1-6.

81. Riley EC, Murphy G, Riley RL: Airborne spread of measles in a suburban elementary school. Am J Epidemiol 1978, 107:421-432.

82. Foxwell AR, Roberts L, Lokuge K, Kelly PM: Transmission of influenza on international flights, may 2009. Emerg Infect Dis 2011, 17:1188-1194.

83. Nardell EA: Environmental control of tuberculosis. Med Clin North Am 1993, 77:1315-1334.

84. Ko G, Thompson KM, Nardell EA: Estimation of tuberculosis risk on a commercial airliner. Risk Anal 2004, 24:379-388.

85. Chen SC, Liao CM, Li SS, You SH: A probabilistic transmission model to assess infection risk from Mycobacterium tuberculosis in commercial passenger trains. Risk Anal 2011, 31:930-939.

86. Wagner BG, Coburn BJ, Blower S: Calculating the potential for withinflight transmission of influenza A (H1N1). BMC Med 2009, 7:81.

87. Liao CM, Chang CF, Liang HM: A probabilistic transmission dynamic model to assess indoor airborne infection risks. Risk Anal 2005, 25:1097-1107.

88. Rudnick SN, Milton DK: Risk of indoor airborne infection transmission estimated from carbon dioxide concentration. Indoor Air 2003, 13:237-245.

89. Riley RL, Mills CC, O'Grady F, Sultan LU, Wittstadt F, Shivpuri DN: Infectiousness of air from a tuberculosis ward. Ultraviolet irradiation of infected air: comparative infectiousness of different patients. Am Rev Respir Dis 1962, 85:511-525.

90. Wells WF, Ratcliffe HL, Grumb C: On the mechanics of droplet nuclei infection; quantitative experimental air-borne tuberculosis in rabbits. Am J Hyg 1948, 47:11-28.

91. Fabian P, McDevitt JJ, DeHaan WH, Fung RO, Cowling BJ, Chan KH, Leung GM, Milton DK: Influenza virus in human exhaled breath: an observational study. PLoS One 2008, 3:e2691.

92. Haas CN, Rose JB, Gerba CP: Quantitative Microbial Risk Assessment New York: John Wiley; 1999.

93. Crawford-Brown DJ: Mathematical Methods of Environmental Risk Modelling Kluwer Academic Publishers; 2001

94. Teunis PF, Brienen N, Kretzschmar ME: High infectivity and pathogenicity of influenza A virus via aerosol and droplet transmission. Epidemics 2010, 2:215-222.

95. Colizza V, Barrat A, Barthelemy M, Vespignani A: The role of the airline transportation network in the prediction and predictability of global epidemics. Proc Natl Acad Sci USA 2006, 103:2015-2020.

96. Khan K, Arino J, Hu W, Raposo P, Sears J, Calderon F, Heidebrecht C, Macdonald M, Liauw J, Chan A, Gardam M: Spread of a novel influenza A (H1N1) virus via global airline transportation. N Engl J Med 2009, 361:212-214.

97. Flahault $A$, Vergu E, Boelle PY: Potential for a global dynamic of Influenza A (H1N1). BMC Infect Dis 2009, 9:129.

98. Kenah E, Chao DL, Matrajt L, Halloran ME, Longini IM Jr: The global transmission and control of influenza. PLoS One 2011, 6:e19515.

99. Hollingsworth $T D$, Ferguson NM, Anderson RM: Will travel restrictions control the international spread of pandemic influenza? Nat Med 2006, 12(5):497-499

100. Cooper BS, Pitman RJ, Edmunds WJ, Gay NJ: Delaying the international spread of pandemic influenza. PLoS Med 2006, 3:e212.

101. Scalia Tomba G, Wallinga J: A simple explanation for the low impact of border control as a countermeasure to the spread of an infectious disease. Math Biosci 2008, 214:70-72. 
102. Colizza V, Barrat A, Barthelemy M, Valleron AJ, Vespignani A: Modeling the worldwide spread of pandemic influenza: baseline case and containment interventions. PLOS Med 2007, 4:e13.

103. Albert R, Barabasi AL: Statistical mechanics of complex networks. Rev Mod Phy 2002, 74:47-97.

104. Newman MEJ: The structure and function of networks. Comp Phys Comm 2002, 147:40-45.

105. Shi $P$, Keskinocak $P$, Swann JL, Lee BY: The impact of mass gatherings and holiday traveling on the course of an influenza pandemic: a computational model. BMC Public Health 2010, 10:778.

106. Germann TC, Kadau K, Longini IM Jr, Macken CA: Mitigation strategies for pandemic influenza in the United States. Proc Natl Acad Sci USA 2006, 103:5935-5940.

107. Longini IM Jr, Nizam A, Xu S, Ungchusak K, Hanshaoworakul W, Cummings DA, Halloran ME: Containing pandemic influenza at the source. Science 2005, 309:1083-1087.

108. Lipsitch M, Riley S, Cauchemez S, Ghani AC, Ferguson NM: Managing and reducing uncertainty in an emerging influenza pandemic. $N$ Engl J Med 2009, 361:112-115.

109. Wu JT, Cowling BJ, Lau EH, Ip DK, Ho LM, Tsang T, Chuang SK, Leung PY, Lo SV, Liu SH, Riley S: School closure and mitigation of pandemic (H1N1) 2009, Hong Kong. Emerg Infect Dis 2010, 16:538-541.

110. Riley S, Ferguson NM: Smallpox transmission and control: spatial dynamics in Great Britain. Proc Natl Acad Sci USA 2006, 103:12637-12642.

111. Egan JR, Hall IM, Leach S: Stamping out fires! Controlling smallpox with targeted mass vaccination. Med Decis Making 2011, 31:69-78.

112. Conway JM, Tuite AR, Fisman DN, Hupert N, Meza R, Davoudi B, English K, van den Driessche P, Brauer F, Ma J, Meyers LA, Smieja M, Greer A, Skowronski DM, Buckeridge DL, Kwong JC, Wu J, Moghadas SM, Coombs D, Brunham RC, Pourbohloul B: Vaccination against 2009 pandemic H1N1 in a population dynamical model of Vancouver, Canada: timing is everything. BMC Public Health 2011, 11:932.

113. Chowell G, Viboud C, Wang X, Bertozzi SM, Miller MA: Adaptive vaccination strategies to mitigate pandemic influenza: Mexico as a case study. PLoS One 2009, 4:e8164.

114. Medlock J, Meyers LA, Galvani A: Optimizing allocation for a delayed influenza vaccination campaign. PLoS Curr 2009, 1:RRN1134.

115. Increased transmission and outbreaks of measles - European region, 2011. MMWR Morb Mortal Wkly Rep 60:1605-1610.

116. Tang S, Xiao Y, Yuan L, Cheke RA, Wu J: Campus quarantine (Fengxiao) for curbing emergent infectious diseases: lessons from mitigating $\mathrm{A} / \mathrm{H} 1 \mathrm{~N} 1$ in Xi'an, China. J Theor Biol 2012, 295:47-58.

117. Miller MA, Viboud C, Balinska M, Simonsen L: The signature features of influenza pandemics - implications for policy. N Engl J Med 2009, 360:2595-2598.

118. Mereckiene J, Cotter S, Weber JT, Nicoll A, D'Ancona F, Lopalco PL, Johansen K, Wasley AM, Jorgensen P, Lévy-Bruhl D, Giambi C, Stefanoff P, Dematte L, O'Flanagan D: Influenza A(H1N1)pdm09 vaccination policies and coverage in Europe. Euro Surveill 2012, 17.

119. EGMN: Notes from the road. Will the UK Win Gold in Public Health Preparedness?. [http://egmnblog.wordpress.com/2012/04/05/will-the-ukwin-gold-in-public-health-preparedness/].

120. NHS London. Getting fit for the 2012 Games. [http://www.london.nhs.uk/ getting-fit-for-the-2012-games].

121. Health Protection Agency. The London 2012 Olympic and Paralympic Games. [http://www.hpa.org.uk/Topics/EmergencyResponse/2012Olympics/].

122. Brownstein JS, Freifeld CC, Chan EH, Keller M, Sonricker AL, Mekaru SR, Buckeridge DL: Information technology and global surveillance of cases of 2009 H1N1 influenza. N Engl J Med 2010, 362:1731-1735.

123. Halloran ME, Ferguson NM, Eubank S, Longini IM Jr, Cummings DA, Lewis B, Xu S, Fraser C, Vullikanti A, Germann TC, Wagener D, Beckman R, Kadau K, Barrett C, Macken CA, Burke DS, Cooley P: Modeling targeted layered containment of an influenza pandemic in the United States. Proc Natl Acad Sci USA 2008, 105:4639-4644.

124. Wu JT, Ho A, Ma ES, Lee CK, Chu DK, Ho PL, Hung IF, Ho LM, Lin CK, Tsang T, Lo SV, Lau YL, Leung GM, Cowling BJ, Peiris JS: Estimating infection attack rates and severity in real time during an influenza pandemic: analysis of serial cross-sectional serologic surveillance data. PLOS Med 2012, 8:e1001103.

\section{Pre-publication history}

The pre-publication history for this paper can be accessed here: http://www.biomedcentral.com/1741-7015/10/159/prepub

doi:10.1186/1741-7015-10-159

Cite this article as: Chowell et al:: Modeling rapidly disseminating infectious disease during mass gatherings. BMC Medicine 2012 10:159.

\section{Submit your next manuscript to BioMed Central and take full advantage of:}

- Convenient online submission

- Thorough peer review

- No space constraints or color figure charges

- Immediate publication on acceptance

- Inclusion in PubMed, CAS, Scopus and Google Scholar

- Research which is freely available for redistribution

Submit your manuscript at www.biomedcentral.com/submit
Biomed Central 